\title{
Inhibiting GLUT-1 expression and PI3K/Akt signaling using apigenin improves the radiosensitivity of laryngeal carcinoma in vivo
}

\author{
YANG-YANG BAO ${ }^{1 *}$, SHUI-HONG ZHOU ${ }^{1 *}$, ZHONG-JIE LU $^{2}$, JUN FAN $^{3}$ and YA-PING HUANG ${ }^{3}$ \\ Departments of ${ }^{1}$ Otolaryngology and ${ }^{2}$ Radiotherapy; \\ ${ }^{3}$ State Key Laboratory for Diagnosis and Treatment of Infectious Diseases, The First Affiliated Hospital, \\ College of Medicine, Zhejiang University, Hangzhou, Zhejiang 310003, P.R. China
}

Received May 20, 2015; Accepted June 24, 2015

DOI: $10.3892 /$ or.2015.4158

\begin{abstract}
Hypoxia is an important factor in radioresistance of laryngeal carcinoma. Glucose transporter-1 (GLUT-1) is an important hypoxic marker in malignant tumors, including laryngeal carcinoma. Apigenin is a natural phytoestrogen flavonoid that has potential anticancer effects. Various studies have reported that the effects of apigenin on lowering GLUT-1 expression were involved in downregulation of the PI3K/Akt pathway. Thus, apigenin may improve the radiosensitivity of laryngeal carcinoma by suppressing the expression of GLUT-1 via the PI3K/Akt pathway. The effect of GLUT-1 and PI3K/Akt pathway-related factor expressions by apigenin or antisense oligonucleotides (AS-ODNs) on the radiosensitivity of laryngeal carcinoma in vivo was assessed. The xenograft volume, xenograft weight and apoptosis detection were performed to determine radiosensitivity. The results showed that apigenin or apigenin plus GLUT-1 AS-ODNs improved the radiosensitivity of xenografts. Apigenin or apigenin plus GLUT-1 reduced the expression of GLUT-1, Akt, and PI3K mRNA after X-ray radiation. We found similar results at the protein level. The results suggest that the effects of apigenin on inhibiting xenograft growth and enhancing xenograft radiosensitivity may be associated with suppressing the expression of GLUT-1 via the PI3K/ Akt pathway. In addition, apigenin may enhance the effects of GLUT-1 AS-ODNs via the same mechanism.
\end{abstract}

Correspondence to: Dr Zhong-Jie Lu, Department of Radiotherapy, The First Affiliated Hospital, College of Medicine, Zhejiang University, 79 Qingchun Road, Hangzhou, Zhejiang 310003, P.R. China

E-mail: luzhongjielzj@163.com

${ }^{*}$ Contributed equally

Abbreviations: AS-ODNs, antisense oligonucleotides; GLUT-1, glucose transporter-1

Key words: laryngeal carcinoma, GLUT-1, apigenin, PI3K/Akt signaling, xenograft, radiosensitivity

\section{Introduction}

Laryngeal carcinoma, the second most common head and neck type of cancer, accounts for $2 \%$ of all malignant tumors worldwide (1). Although a variety of surgical procedures, radiotherapy, chemotherapy or combination therapies are used in its treatment (2), the statistics reported by the American Cancer Society in 2014 indicated that the 5-year survival rate of patients with laryngeal carcinoma has decreased between 1975 and 2009 (3). Therefore, novel treatment strategies are needed to improve the survival rate of patients with laryngeal carcinoma and preserve the function of their larynx. Radiation therapy plays an important role in patients with early and late stage, and recurrent laryngeal carcinoma, however, radioresistance is common, leading to the treatment failure of radiation therapy (4-6). Therefore, developing a novel therapeutic strategy is necessary to improve the radiosensitivity of laryngeal carcinoma.

Resistance to head and neck cancer radiotherapy occurs for three main reasons: intrinsic radiation resistance, tumor cell proliferation and hypoxia. It has been previously reported that hypoxia plays an important role in the resistance of tumors to radiotherapy (7). GLUT-1 is an important hypoxic marker in various malignant tumors, including laryngeal carcinoma (8-13). Previous findings have shown that antisense oligonucleotides (AS-ODNs) against GLUT-1 inhibited glucose uptake and the proliferation in Hep-2 cells by inhibiting the expression of GLUT-1 (14). Additional studies found that the radioresistance of laryngeal cancer was associated with a high expression of GLUT-1 and that the radiosensitivity of laryngeal carcinoma could be increased by suppressing the expression of GLUT-1 using GLUT-1 AS-ODNs (15). The abnormal expression of GLUT-1 activates a variety of signal transduction pathways and the PI3K/Akt signaling pathway plays an important role in regulating the expression of GLUT-1 (16-19). Activation of the PI3K/Akt signaling pathway is also associated with the radioresistance and chemoradioresistance of tumors (20-26). To the best of our knowledge, no studies have assessed the effects of PI3K/Akt signaling on GLUT-1 expression and their relationship with the radioresistance of laryngeal carcinoma in vivo. 
Apigenin is a natural phytoestrogen flavonoid present in a wide range of fruits, vegetables (particularly celery), beans and tea. Moreover, in vitro and in vivo studies have demonstrated that apigenin exerts potential biological effects, including anti-oxidative, anti-inflammatory and anticancer activities, with the antitumor effects being the most prominent (27). Apigenin inhibits PI3K/Akt signaling in human types of cancer $(16,28-33)$ and previous findings have shown that the effects of apigenin on lowering GLUT-1 expression were involved in downregulation of the PI3K/Akt pathway $(16,32)$. We demonstrated previously that the overexpression of GLUT-1 and p-Akt was associated with the resistance laryngeal carcinoma Hep-2 cells to cisplatin. Additionally, apigenin was able to suppress GLUT-1 and p-AKT expression to enhance the chemosensitivity of laryngeal carcinoma to cisplatin (32). However, to the best of our knowledge, no studies have assessed the effects of apigenin on the PI3K/Akt pathway, GLUT-1 expression and the radiosensitivity of tumors.

The aim of the present study was to examine the expression of GLUT-1 and PI3K/Akt pathway-related factors in tumors in nude mice. Specifically, we investigated whether GLUT-1 expression was decreased by inhibiting the PI3K/Akt pathway and whether apigenin enhanced the radiosensitivity of laryngeal carcinoma. In addition, we assessed whether apigenin plays a role in the effects of GLUT-1 AS-ODNs on enhancing the radiosensitivity of laryngeal carcinoma.

\section{Materials and methods}

Reagents. Apigenin was purchased from Selleckchem (Houston, TX, USA). AS-ODNs GLUT-1 was prepared as reported previously $(14,15)$. TRIzol was obtained from Invitrogen (Carlsbad, CA, USA; cat. no. 15596-026). The cDNA First-Strand Synthesis kit and Taq DNA polymerase were obtained from Thermo Fisher Scientific (Waltham, MA, USA; cat. nos k1622 and ep0405, respectively). Real-Time PCR Master Mix (SYBR ${ }^{\circledR}$-Green) was purchased from Toyobo (Tokyo, Japan). Agarose was obtained from Biowest (Madrid, Spain; cat. no 111860). The 50X TAE electrophoresis buffer, chloroform and isopropanol were purchased from the Nanjing Chemical Reagent Co. Ltd. (Nanjing, China). The terminal deoxynucleotidyl transferase-mediated dUTP digoxigenin nick end-labeling (TUNEL) staining of tumor sections was performed using an in situ apoptosis detection kit purchased from Roche (Shanghai, China). The following reagents were obtained from Hangzhou Biotech Co., Ltd. (Hangzhou, China): 70\% ethanol [treated with diethylpyrocarbonate, (DEPC)], water containing 0.1\% DEPC, a total protein extraction kit, a Bradford protein detection kit, $5 \mathrm{X}$ sodium dodecyl sulfate-polyacrylamide gel electrophoresis (SDS-PAGE) protein loading buffer, pre-stained protein molecular weight markers, 10X Tris-glycine protein electrophoresis buffer, a Coomassie Blue staining kit, 10X transfer buffer, Ponceau S staining solution, 10X western blot analysis (WB) washing buffer, WB blocking solution, primary antibody dilution buffer, secondary antibody dilution buffer, WB stripping buffer and an ECL WB detection kit.

Cell culture. The laryngeal Hep-2 carcinoma cell line was purchased from the Cell Research Institute of the Chinese Academy of Sciences (Shanghai, China). The cells were cultured at the Roswell Park Memorial Institute-1640 (RPMI-1640; Gibco-BRL, Gaithersburg, MD, USA) supplemented with $10 \%$ heat-inactivated fetal bovine serum (FBS; Hyclone, Logan, UT, USA), $100 \mathrm{U} / \mathrm{ml}$ penicillin and $100 \mathrm{~g} / \mathrm{ml}$ streptomycin at $37^{\circ} \mathrm{C}$ in an atmosphere containing $5 \% \mathrm{CO}_{2}$. Cells in the logarithmic growth phase were used in the experiments.

Nude mouse model of laryngeal carcinoma. This experiment was conducted in accordance with the institutional guidelines of the First Affiliated Hospital, College of Medicine, Zhejiang University and with appropriate institutional certification. Four-week-old male athymic nude mouse with a BALB/c background weighing $18 \pm 2 \mathrm{~g}(\mathrm{n}=30)$ were raised under specific pathogen-free (SPF) conditions at the Surgical Laboratory Animal Center of the First Affiliated Hospital, College of Medicine, Zhejiang University. Under sterile conditions, a $2 \times 10^{6} / \mathrm{ml}$ Hep-2 cell suspension was injected subcutaneously into the right forelimb of each nude mouse at a volume of $0.2 \mathrm{ml}$. The inoculation site of each nude mouse was observed daily after inoculation. After 1 week, a grain-sized induration may develop at the visible inoculation site, which confirmed that the xenograft model was established successfully.

Grouping and intervention. Two separate experiments were performed: one using 15 and a second using 18 tumor-bearing mice.

Experiment $1(n=15)$. When the tumors reached a volume of $\sim 100 \mathrm{~mm}^{3}, 15$ tumor-bearing mice were divided randomly into five groups of three mice. The tumors were then treated as follows: $50 \mu \mathrm{g}$ apigenin combined with $10 \mathrm{~Gy} \mathrm{X}$-ray irradiation, $100 \mu \mathrm{g}$ apigenin combined with $10 \mathrm{~Gy} \mathrm{X}$-ray irradiation, $50 \mu \mathrm{g}$ apigenin alone, $100 \mu \mathrm{g}$ apigenin alone and $10 \mathrm{~Gy} \mathrm{X}$-ray irradiation alone. The apigenin was dissolved in dimethyl sulfoxide (DMSO) and then diluted in serum-free RPMI-1640 medium to achieve a final DMSO concentration of $0.1 \%$. In the animals treated with 50 or $100 \mu \mathrm{g}$ apigenin and $10 \mathrm{~Gy} \mathrm{X}$-ray irradiation, the mice were injected intraperitoneally with 50 or $100 \mu \mathrm{g}$ apigenin once daily for 10 days (the interval time was 1 day). The local tumor was then irradiated with $10 \mathrm{~Gy}$ X-ray irradiation on day 20 and the tumors were observed for 1 week. In the animals treated with 50 or $100 \mu \mathrm{g}$ apigenin, the mice were injected intraperitoneally with 50 or $100 \mu \mathrm{g}$ apigenin once daily for 10 days (the interval time was 1 day) and the tumors were observed for 1 week. In animals that received 10 Gy X-ray irradiation alone, the local tumor was irradiated with 10 Gy X-ray irradiation on day 20 and the tumors were observed for 1 week. All the mice were sacrificed on day 27 and the tumors were resected and stored at $-80^{\circ} \mathrm{C}$ until analysis.

Experiment $2(n=18)$. When the tumors reached a volume of $\sim 100 \mathrm{~mm}^{3}, 18$ tumor-bearing mice were divided randomly into six groups of three mice: A negative control, apigenin alone, GLUT-1 AS-ODNs alone, 10 Gy X-ray irradiation alone, apigenin and GLUT-1 AS-ODNs and the combination of apigenin, GLUT-1 AS-ODNs and 10 Gy X-ray irradiation. In the apigenin-only group, the mice were injected intraperitoneally with $100 \mu \mathrm{g}$ apigenin daily for 10 consecutive days. In the GLUT-1 AS-ODNs-only group, the mice were injected peritumorally with $100 \mu$ g GLUT-1 AS-ODNs three 
times at 2-day intervals. The mice treated with apigenin and GLUT-1 AS-ODNs were injected intraperitoneally with $100 \mu \mathrm{g}$ apigenin daily for 10 consecutive days and also injected peritumorally with $100 \mu \mathrm{g}$ GLUT-1 AS-ODNs three times at 2-day intervals. Mice in the apigenin, GLUT-1 AS-ODNs and 10 Gy X-ray irradiation combination group were treated as described for the apigenin and GLUT-1 AS-ODNs group and 10 Gy X-ray irradiation was administered locally at the tumor site on day 10 . Mice in the $10 \mathrm{~Gy}$ X-ray irradiation-only group received $10 \mathrm{~Gy}$ irradiation at the tumor site on day 10 . The mice were sacrificed on day 24 and the tumors were resected and stored at $-80^{\circ} \mathrm{C}$ until analysis.

Observation. The mental state, food intake and activity of all the mice were monitored daily. The tumor growth conditions (tumor formation rate, size, weight and inhibition ratio) were assessed after vaccination, drug and radiological intervention. The tumor volume (V) was calculated by measuring the i) long and ii) short tumor diameter after tumor formation using the equation $\mathrm{V}=1 / 2\left(a b^{2}\right)$. The tumor formation rate was calculated as the number of mice whose tumor volume was $>5 \mathrm{~mm}$ diameter/the number of the mice in the experimental group x $100 \%$. Animal surgery was performed under general anesthesia, using $50 \mathrm{mg} / \mathrm{kg}$ ip injection of pentobarbital sodium. The inhibition ratio (IR) was defined as 1-(tumor weight of test group/control group).

Measuring GLUT-1,p-Akt and PI3K mRNA using reverse transcription-quantitative polymerase chain reaction (RT-qPCR). Total RNA was extracted from cells using TRIzol according to the manufacturer's instructions. The concentration of totalRNA was measured using ultraviolet spectrophotometry, with an optical density (OD) 260/280 ratio of 1.8-2.1 being considered acceptable. First-strand cDNA was synthesized in a $20-\mu 1$ reaction in $0.2-\mathrm{ml}$ sterile and nuclease-free PCR tubes comprising: $\mathrm{n} \mu \mathrm{l}$ (?) of RNA (total $2 \mu \mathrm{g}$ ), $2 \mu \mathrm{l}$ reaction volume consisting of $50 \mu \mathrm{M}$ of oligo d(18) primer, and $\mathrm{DEPC} \cdot \mathrm{H}_{2} \mathrm{O}$ at a total volume of $12.5 \mu \mathrm{l}$. Reactions were incubated at $65^{\circ} \mathrm{C}$ for $5 \mathrm{~min}$, placed on ice for $5 \mathrm{~min}$ and the following components were then added: $0.5 \mu \mathrm{l}$ of RNase inhibitor (40 U/ $\mu \mathrm{l}), 4.0 \mu 15 \mathrm{X}$ reaction buffer, $2.0 \mu \mathrm{l} \mathrm{dNTPs}(10 \mathrm{mM})$ and $1.0 \mu \mathrm{l} \mathrm{M-MuLV}$. After gentle mixing, the tubes were centrifuged at 2,000 rpm for $20 \mathrm{sec}$ and then incubated at $42^{\circ} \mathrm{C}$ for $1 \mathrm{~h}, 70^{\circ} \mathrm{C}$ for $10 \mathrm{~min}$ and placed on ice for $5 \mathrm{~min}$. The resulting product was then used immediately in the next step PCR reaction or stored at $-20^{\circ} \mathrm{C}$. According to a certain order, a sample of the gene was repeated for three wells. The following components were added to the 0.2-ml PCR tubes: $10 \mu 12 \mathrm{X}$ real-time PCR master mix (SYBR ${ }^{\circledR}$-Green), $1 \mu 1$ cDNA template (diluted 10-fold), $2 \mu \mathrm{l}$ primer mix (10 $\mu \mathrm{M}$ of each forward and reverse primer) and $7 \mu \mathrm{l} 0.1 \%$ DEPC $\mathrm{H}_{2} \mathrm{O}$, in a total volume of $20 \mu \mathrm{l}$. The primer sequences and the length of the resulting PCR products were as follows: GAPDH (202 bp) forward, 5'-TGTTGCCAT CAATGACCCCTT-3' and reverse, 5'-CTCCACGACGTA CTCAGCG-3'; GLUT1 (111 bp) forward, 5'-GTCAACACG GCCTTCACTG-3' and reverse, 5'-GGTCATGAGTAT GGCACAACC-3'; Akt (67 bp) forward, 5'-GCAGCACGGTAC GAGAAGA-3' and reverse, 5'-GGTGTCAGTCTCCGAC GTG-3'; and PI3K (144 bp) forward, 5'-GGGGATGAT TTACGGCAAGATA-3' and reverse, 5'-CACCACCTC AATAAGTCCCACA-3'. To distinguish between specific and non-specific products and primer dimers, a dissociation curve analysis was conducted immediately after amplification by continuous monitoring of the SYBR ${ }^{\circledR}$-Green I fluorescence signal at temperatures between 60 and $95^{\circ} \mathrm{C}$. For calculation of the differential gene expression, the $2^{-\Delta \Delta \mathrm{Ct}}$ formula was used.

Western blot analysis. GLUT-1, p-Akt and PI3K protein levels were analyzed using a BAC protein quantification kit. Briefly, $80 \mu \mathrm{g}$ of protein was separated using 10\% SDS-PAGE and transferred to nitrocellulose membranes. The membranes were blocked in PBST solution (phosphate-buffered saline with Tween-20) containing 5\% skim milk at room temperature for $1 \mathrm{~h}$ and incubated with primary antibodies (anti-actin, 1:4,000 dilution; GLUT-1, 1:800; p-Akt, 1:1,000; PI3K, 1:800) at $4^{\circ} \mathrm{C}$ overnight. The membranes were then incubated with secondary antibodies (donkey anti-rabbit, 1:5,000; donkey anti-mouse, $1: 2,000)$ at room temperature for $1 \mathrm{~h}$. The proteins were visualized using enhanced chemiluminescence and exposed to X-ray film. Protein expression was analyzed semiquantitatively using a Gel Logic analysis system (Kodak, Rochester, NY, USA).

TUNEL assays. Paraffin-embedded sections of xenograft tumor tissues were dewaxed and hydrated. TUNEL staining of tumor sections was then performed according to the manufacturer's instructions (Roche). Staining was visualized under an optical microscope, and cells with brown or brown-yellow nuclei were interpreted as positive and observations were confirmed using the morphological features of apoptotic cells. Specifically, unstained cells became smaller, the membrane appeared to be foaming, apoptotic bodies formed in the later stages and adherent cells became shrunken, round and shed. In addition, stained cells exhibited chromatin condensation, marginalization, nuclear membrane cracking and the chromatin was divided into block/apoptotic bodies. The sections were observed at a magnification of $\mathrm{x} 400$ and the percentage of apoptotic cells in 100 cells/field was counted and used to calculate the mean apoptosis index (AI).

\section{Results}

General observations. Subcutaneous xenograft tumors were visible $\sim 1$ week after inoculation with Hep-2 cells (Fig. 1A) and appeared as round or oval nodules. Mice in each group exhibited no obvious abnormalities in mental behavior, eating habits, defecation or mortality during the experimental period. Of the 33 mice inoculated in the present study, the tumor formation rate was $100 \%$ and the tumor volume reached $\sim 100 \mathrm{~mm}^{3}$ after 2 weeks (Fig. 1B).

\section{Xenografts}

Xenograft volume. In the first experiment, tumor size in the $100 \mu \mathrm{g}$ apigenin group decreased significantly compared to the 10 Gy group after 12 days of treatment $(\mathrm{P}<0.05$; Fig. $2 \mathrm{~A})$. However, no significant differences in tumor volume were observed among the remaining groups $(\mathrm{P}>0.05)$. By contrast, tumor size decreased in the 50,100,50 $\mu \mathrm{g}$ apigenin plus $10 \mathrm{~Gy}$ and $100 \mu \mathrm{g}$ apigenin plus $10 \mathrm{~Gy}$ groups compared to the 10 GY group after 19 days of treatment $(\mathrm{P}<0.05$; Fig. 2A). After X-ray radiation, tumors were significantly smaller in the $100 \mu \mathrm{g}$ apigenin plus $10 \mathrm{~Gy}$ group compared to the 

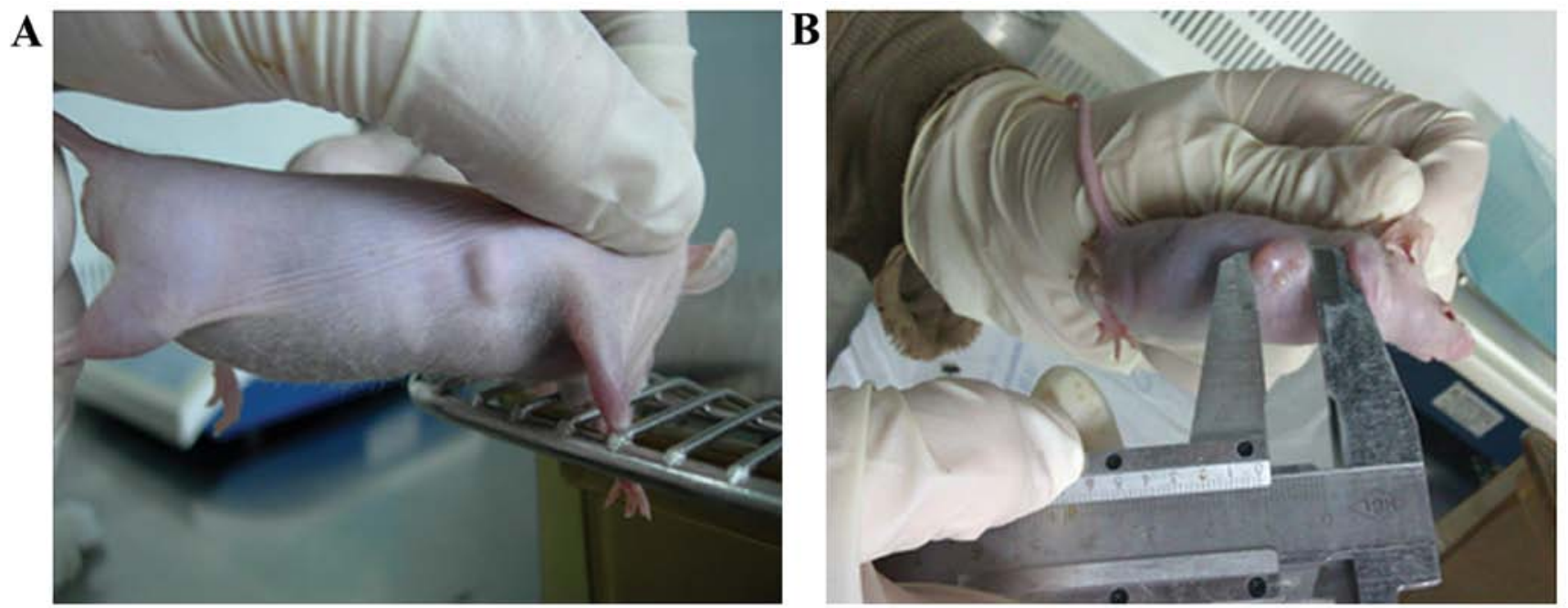

Figure 1. Establishment of the nude mouse model of laryngeal carcinoma. (A) Subcutaneous xenograft tumors were visible 1 week after inoculation with Hep-2 cells. (B) Tumor volume reached $\sim 100 \mathrm{~mm}^{3}$ after 2 weeks.

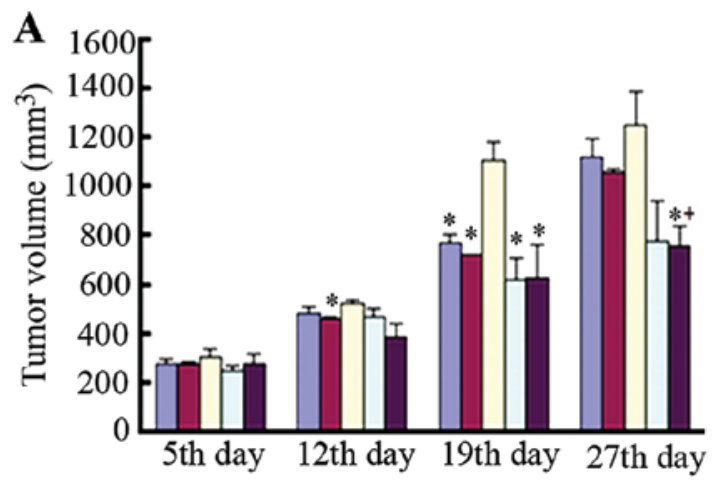

$\square$ Apigenin $50 \mu$ g group

$\square$ Apigenin $100 \mu$ group

$\square 10$ Gy group

$\square$ Apigenin $50 \mu \mathrm{g}+10 \mathrm{~Gy}$ group

$\square$ Apigenin $100 \mu \mathrm{g}+10$ Gy group

\section{B}

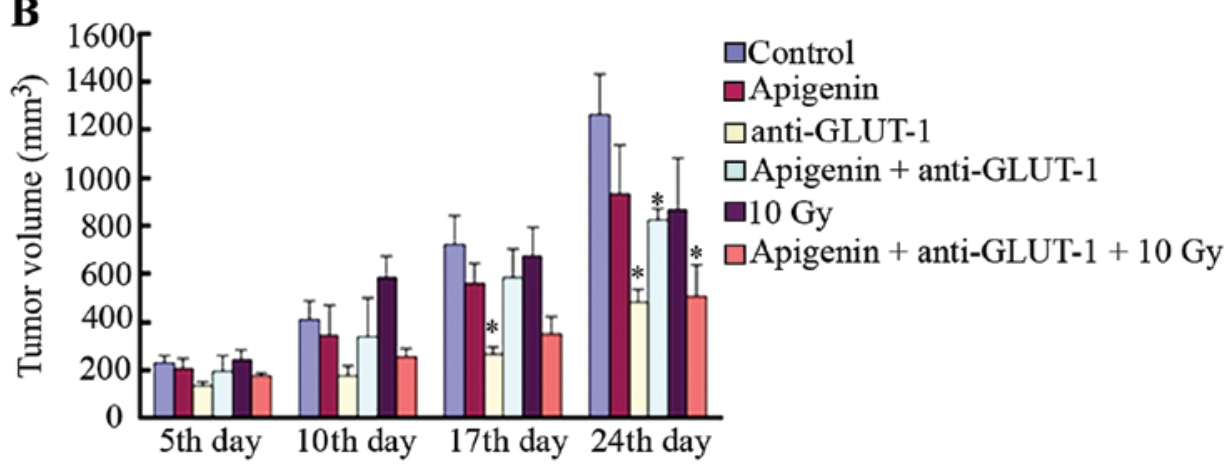

Figure 2. The effects of apigenin, GLUT-1 AS-ODNs or the combined treatment plus radiation on xenograft tumor growth in vivo. (A) In the first experiment, the tumor volume of each treatment group on the 5 th, 12 th, 19 th and 27 th day. ${ }^{*} \mathrm{P}<0.05$, indicated that there were significant differences in the tumor volume compared to the $10 \mathrm{~Gy}$ group. ${ }^{+} \mathrm{P}<0.05$, indicated that there were significant differences in tumor volume between the apigenin $100 \mu \mathrm{g}+10 \mathrm{~Gy}$ group and apigenin $100 \mu$ g group. (B) In the second experiment, the tumor volume of each treatment group on the 5 th, 10 th, 17 th and 24 th day. ${ }^{*}<<0.05$, indicated that there were significant differences in the tumor volume compared to the control group.

10 Gy group 27 days after treatment $(\mathrm{P}<0.05$; Fig. $2 \mathrm{~A})$ However, no significant differences were detected between tumors in the $50 \mu \mathrm{g}$ apigenin plus $10 \mathrm{~Gy}$ and $10 \mathrm{~Gy}$ alone groups, 50 and $100 \mu \mathrm{g}$ apigenin groups, $50 \mu \mathrm{g}$ apigenin plus $10 \mathrm{~Gy}$ and $50 \mu \mathrm{g}$ apigenin alone groups and the $50 \mu \mathrm{g}$ apigenin plus $10 \mathrm{~Gy}$ and $100 \mu \mathrm{g}$ apigenin plus $10 \mathrm{~Gy}$ groups (all $\mathrm{P}>0.05$ ).

In the second experiment, tumors were significantly smaller in the GLUT-1 AS-ODNs group compared to the control group 17 days after treatment $(\mathrm{P}<0.05$; Fig. $2 \mathrm{~B})$. No significant differences in tumor volume were observed among the remaining groups $(\mathrm{P}>0.05)$. By contrast, tumors were significantly smaller in the GLUT-1 AS-ODNs, apigenin plus GLUT-1 AS-ODNs, apigenin plus GLUT-1 AS-ODNs plus 10 Gy groups compared to the control 24 days after treatment $(\mathrm{P}<0.05$; Fig. 2B).

Xenograft weight. In the first experiment, the weight of the tumors harvested from the mice in each group is 

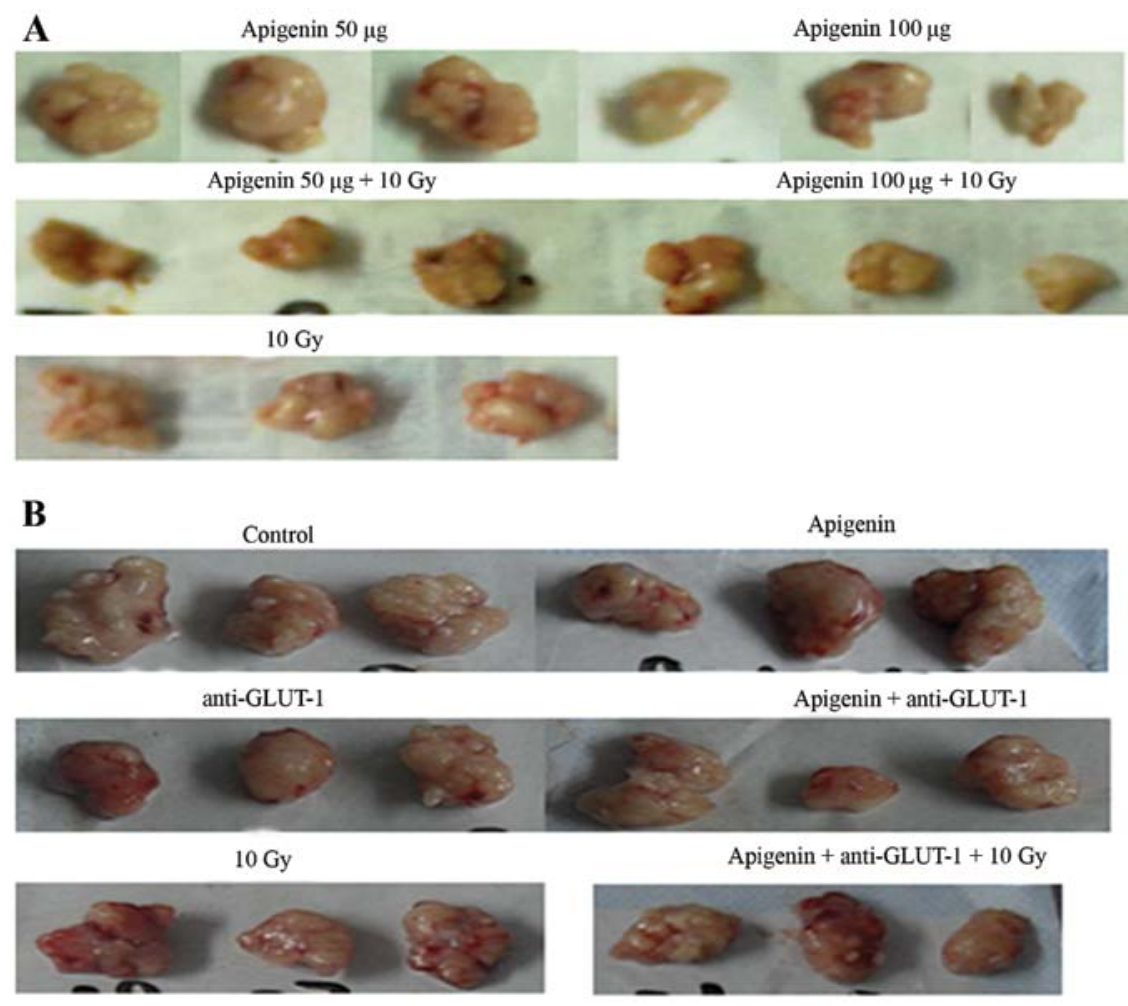

Figure 3. Tumors harvested from the mice in each group. Tumors were resected from the mice in each group of the (A) first experiment and (B) second experiment.

Table I. Tumor weight of each group in the first experiment.

\begin{tabular}{ll}
\hline Group & Tumor weight $(\mathrm{g})$ \\
\hline Apigenin $50 \mu \mathrm{g}$ & $0.6070 \pm 0.0195$ \\
Apigenin $100 \mu \mathrm{g}$ & $0.5260 \pm 0.0285^{\mathrm{a}, \mathrm{b}}$ \\
$10 \mathrm{~Gy}$ & $0.6770 \pm 0.0609$ \\
Apigenin $50 \mu \mathrm{g}+10 \mathrm{~Gy}$ & $0.4937 \pm 0.2430$ \\
Apigenin $100 \mu \mathrm{g}+10 \mathrm{~Gy}$ & $0.4820 \pm 0.1421$ \\
\hline
\end{tabular}

Data are presented as a mean value \pm standard deviation. ${ }^{\mathrm{a}} \mathrm{P}<0.05$, indicated that there were significant differences in tumor weight between the apigenin 100 and $50 \mu \mathrm{g}$ groups. ${ }^{\mathrm{b}} \mathrm{P}<0.05$, indicated that there were significant differences in tumor weight between the apigenin $100 \mu \mathrm{g}$ and $10 \mathrm{~Gy}$ groups.

shown in Fig. 3A. Tumors weighed significantly less in the $100 \mu \mathrm{g}$ apigenin group compared to the $50 \mu \mathrm{g}$ apigenin and 10 Gy group $(\mathrm{P}<0.05$; Table I). No significant differences were identified in the weight of tumors in the $50 \mu \mathrm{g}$ apigenin plus $10 \mathrm{~Gy}$ and $50 \mu \mathrm{g}$ apigenin groups, the $50 \mu \mathrm{g}$ apigenin plus $10 \mathrm{~Gy}$ and $10 \mathrm{~Gy}$ groups, $100 \mu \mathrm{g}$ apigenin plus $10 \mathrm{~Gy}$ and $100 \mu \mathrm{g}$ apigenin groups, $100 \mu \mathrm{g}$ apigenin plus $10 \mathrm{~Gy}$ and $10 \mathrm{~Gy}$ groups, $50 \mu \mathrm{g}$ apigenin plus $10 \mathrm{~Gy}$ and $10 \mathrm{~Gy}$ groups, apigenin $50 \mu \mathrm{g}$ plus $10 \mathrm{~Gy}$ and apigenin $100 \mu \mathrm{g}$ plus $10 \mathrm{~Gy}$ groups $(\mathrm{P}>0.05)$.

The weight of the tumors harvested from the mice in each group from the second experiment is shown in Fig. 3B. GLUT-1 AS-ODNs reduced tumor weight significantly compared to the control $(\mathrm{P}<0.05$; Table II), but no significant differences were observed among the remaining groups $(\mathrm{P}>0.05)$.

Xenograft growth inhibition. In the second experiment, the rates of tumor growth inhibition in the apigenin, GLUT-1 AS-ODNs, $10 \mathrm{~Gy}$, apigenin plus GLUT-1 AS-ODNs and apigenin plus GLUT-1 AS-ODNs plus 10 Gy groups were $-2.05,37.33,7.02,4.79$ and $27.16 \%$, respectively.

Effects of apigenin and GLUT-1 AS-ODNs on xenograft apoptosis. The apoptotic indices were significantly higher in the apigenin, GLUT-1 AS-ODNs, $10 \mathrm{~Gy}$, apigenin plus GLUT-1 AS-ODNs and apigenin plus GLUT-1 AS-ODNs plus $10 \mathrm{~Gy}$ groups compared to the control ( $\mathrm{P}<0.05$; Fig. 4, Table II). The combination of apigenin and GLUT-1 AS-ODNs significantly enhanced the effects of apigenin or GLUT-1 AS-ODNs alone on tumor cell apoptosis ( $\mathrm{P}<0.05$; Fig. 4, Table II). In addition, the combination of apigenin and GLUT-1 AS-ODNs significantly enhanced the effects of X-ray irradiation on tumor cell apoptosis $(\mathrm{P}<0.05$; Fig. 4, Table II).

Effects of apigenin and GLUT-1 AS-ODNs on GLUT-1, Akt, and PI3K $m R N A$. In the first experiment, GLUT-1, Akt and $P I 3 K$ mRNA expression was significantly decreased in the $100 \mu \mathrm{g}$ compared to the $50 \mu \mathrm{g}$ apigenin group ( $\mathrm{P}<0.05$; Fig. 5A). In addition, GLUT-1, Akt, and PI3K mRNA expression was significantly lower in the 100 compared to the $50 \mu \mathrm{g}$ apigenin plus 10 Gy group $(\mathrm{P}<0.05$; Fig. 5A). The expression of GLUT-1 mRNA was significantly reduced in the $100 \mu \mathrm{g}$ apigenin plus 10 Gy group compared to the 10 Gy group $(\mathrm{P}<0.05$; Fig. $5 \mathrm{~A})$. Finally, the expression of GLUT-1, Akt and PI $3 K$ mRNA was 
Table II. Tumor weight, inhibitory rate and apoptotic index of each group in the second experiment.

\begin{tabular}{lcrc}
\hline Group & Tumor weight $(\mathrm{g})$ & Inhibitory rate $(\%)$ & AI $(\%)$ \\
\hline Control & $0.9733 \pm 0.1358$ & $1.50 \pm 1.77$ \\
Apigenin & $0.9933 \pm 0.2108$ & -2.05 & $23.65 \pm 6.41^{\mathrm{b}}$ \\
Anti-GLUT-1 & $0.6100 \pm 0.0346^{\mathrm{a}}$ & 37.33 & $6.63 \pm 3.13^{\mathrm{b}}$ \\
Apigenin+anti-GLUT-1 & $0.9267 \pm 0.6888$ & 4.79 & $34.71 \pm 7.48^{\mathrm{b}, \mathrm{c}}$ \\
10 Gy & $0.9050 \pm 0.1598$ & 7.02 & $15.26 \pm 3.43^{\mathrm{b}}$ \\
Apigenin+anti-GLUT-1+10 Gy & $0.7090 \pm 0.2383$ & 27.16 & $53.28 \pm 5.81^{\mathrm{b}, \mathrm{d}}$ \\
\hline
\end{tabular}

Data are presented as a mean value \pm standard deviation. ${ }^{\mathrm{a}} \mathrm{P}<0.05$, indicated that there were significant differences in the tumor weight compared to the control group. ${ }^{b} \mathrm{P}<0.05$, indicated that there were significant differences in the tumor apoptotic index compared to the control group. ${ }^{c} \mathrm{P}<0.05$, indicated that the combination of apigenin and GLUT-1 AS-ODNs significantly enhanced the effects of apigenin or GLUT-1 AS-ODNs alone on tumor cell apoptosis. ${ }^{\mathrm{d}} \mathrm{P}<0.05$, indicated that the combination of apigenin and GLUT-1 AS-ODNs significantly enhanced the effects of X-ray irradiation on tumor cell apoptosis. AI, apoptotic index.

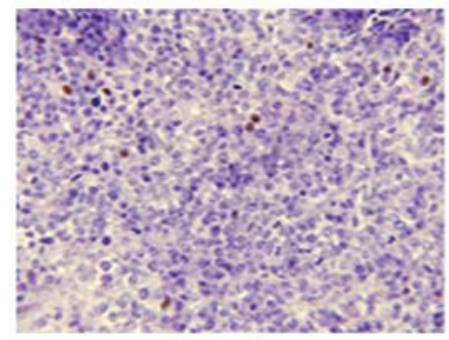

Control

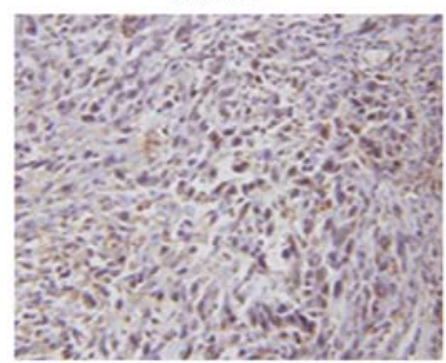

Apigenin + anti-GLUT-1

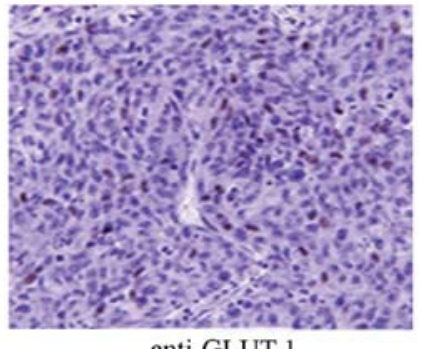

anti-GLUT-1

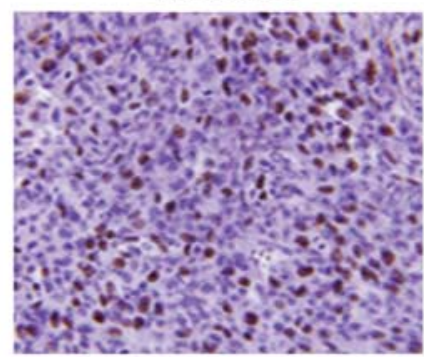

$10 \mathrm{~Gy}$

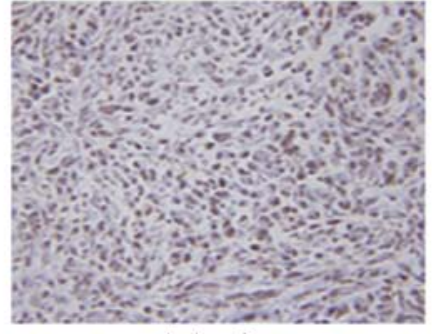

Apigenin

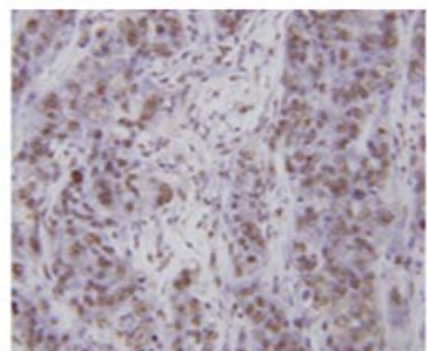

Apigenin + anti-GLUT-1 + 10 Gy

Figure 4. The effects of apigenin and GLUT-1 AS-ODNs on xenograft apoptosis (the second experiment), observed an under optical microscope (magnification, $\mathrm{x} 400$ ), and the percentage of apoptotic cells in 100 cells per field was counted and used to calculate the mean apoptosis index (AI). AI, apoptotic index.

significantly higher in the $50 \mu \mathrm{g}$ apigenin plus $10 \mathrm{~Gy}$ group compared to the 10 Gy $\mathrm{X}$-ray group ( $\mathrm{P}<0.05$; Fig. 5A).

In the second experiment, GLUT-1, Akt and PI3K mRNA expression was significantly decreased in the apigenin group, GLUT-1 AS-ODNs group, apigenin plus GLUT-1 AS-ODNs group and apigenin plus GLUT-1 AS-ODNs plus 10 Gy group compared to the control group $(\mathrm{P}<0.05$; Fig. 5B). In addition, GLUT-1 expression was significantly higher in the $10 \mathrm{~Gy}$ $\mathrm{X}$-ray radiation group than in the control group $(\mathrm{P}<0.05$; Fig. 5B). The expression of $A k t$ and $P I 3 K$ was also higher in the $10 \mathrm{~Gy} \mathrm{X}$-ray radiation group compared to the control group, although it was not significant $(\mathrm{P}>0.05)$. Apigenin plus GLUT-1 AS-ODNs significantly enhanced the effect of inhibition on the expression of GLUT-1 mRNA and PI3K mRNA of apigenin or GLUT-1 AS-ODNs, respectively ( $\mathrm{P}<0.05$; Fig. 5B). The expression of GLUT-1, Akt and PI3K was significantly reduced in the apigenin plus GLUT-1 AS-ODNs plus $10 \mathrm{~Gy}$ group compared to the 10 Gy group $(\mathrm{P}<0.05$; Fig. $5 \mathrm{~B})$.
Effects of apigenin and GLUT-1 AS-ODNs on GLUT-1, $p$-Akt and PI3K expression. In the first experiment, GLUT-1 expression was significantly reduced in the $100 \mu \mathrm{g}$ apigenin plus $10 \mathrm{~Gy}$ group than in the $10 \mathrm{~Gy}$ group $(\mathrm{P}<0.05$; Fig. 6$)$. The expression of PI3K was significantly higher in the 50 and $100 \mu \mathrm{g}$ apigenin plus $10 \mathrm{~Gy}$ groups compared to the 10 Gy $\mathrm{X}$-ray group $(\mathrm{P}<0.05$; Fig. 6). Conversely, the expression of p-Akt was lower in the 50 and $100 \mu \mathrm{g}$ apigenin plus 10 Gy groups, but not significantly $(\mathrm{P}>0.05)$. The expression of GLUT-1, p-Akt and PI3K was lower in the $100 \mu \mathrm{g}$ apigenin plus $10 \mathrm{~Gy}$ group than in the $50 \mu \mathrm{g}$ apigenin group as well as in the $100 \mu \mathrm{g}$ compared to the $50 \mu \mathrm{g}$ apigenin group, although not significantly $(\mathrm{P}>0.05)$.

In the second experiment, the expression of GLUT-1, p-Akt, and PI3K was significantly decreased in the apigenin group, GLUT-1 AS-ODNs group and apigenin plus GLUT-1 AS-ODNs group compared to the control group ( $\mathrm{P}<0.05$; Fig. 7$)$. The expression of GLUT-1 and p-Akt was significantly lower in the 
A
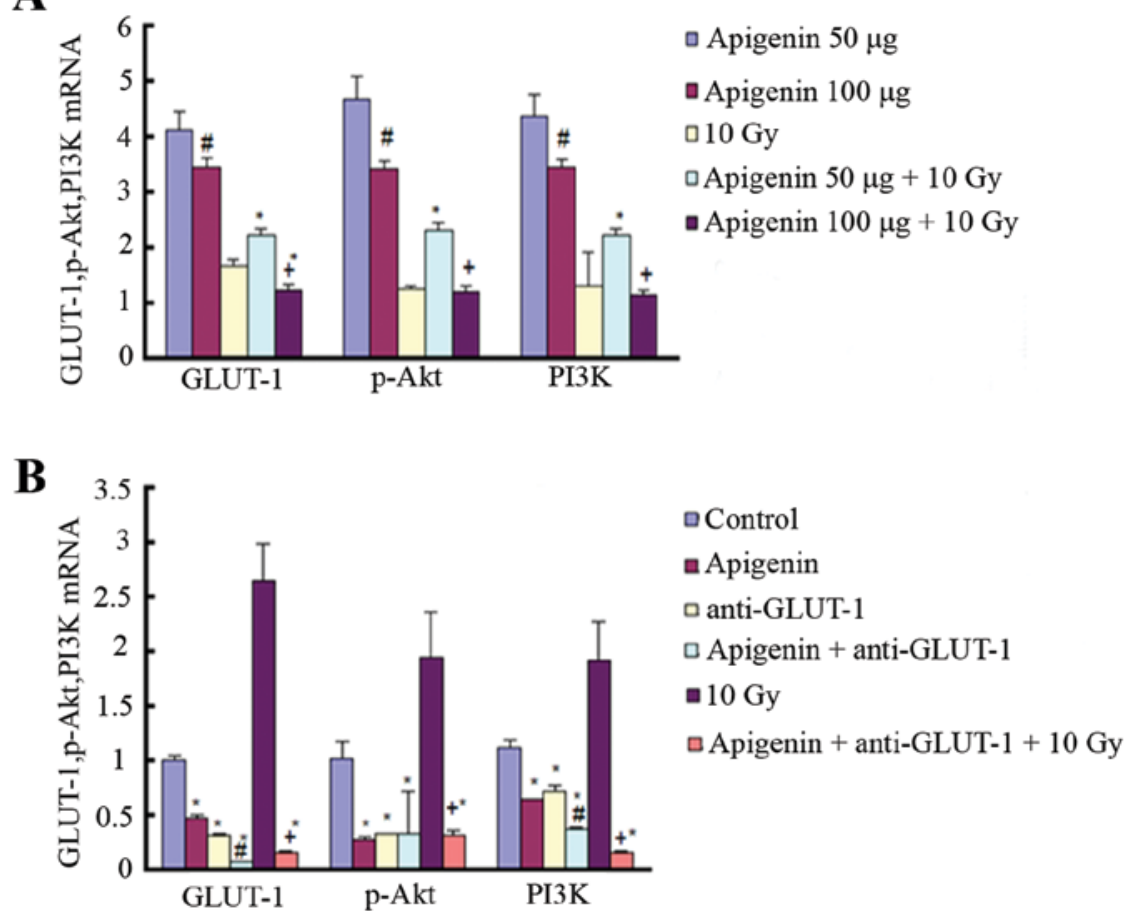

Figure 5. Effects of apigenin and GLUT-1 AS-ODNs on GLUT-1, Akt and PI3K mRNA. (A) First experiment: "P<0.05, indicated that there were significant differences in the tumor mRNA compared to the $10 \mathrm{~Gy}$ group. ${ }^{+} \mathrm{P}<0.05$, indicated that there were significant differences in the tumor mRNA between apigenin $100 \mu \mathrm{g}+10 \mathrm{~Gy}$ group and apigenin $50 \mu \mathrm{g}+10 \mathrm{~Gy}$ group. (B) Second experiment: ${ }^{*} \mathrm{P}<0.05$, indicated that there were significant differences in the tumor mRNA compared to the control group. ${ }^{+} \mathrm{P}<0.05$, indicated that there were significant differences in the tumor mRNA between the apigenin+anti-GLUT- $1+10$ Gy group and 10 Gy group. ${ }^{\#} \mathrm{P}<0.05$, indicated that there were significant differences in the tumor mRNA between the apigenin+anti-GLUT-1 group and apigenin group or anti-GLUT-1 group.

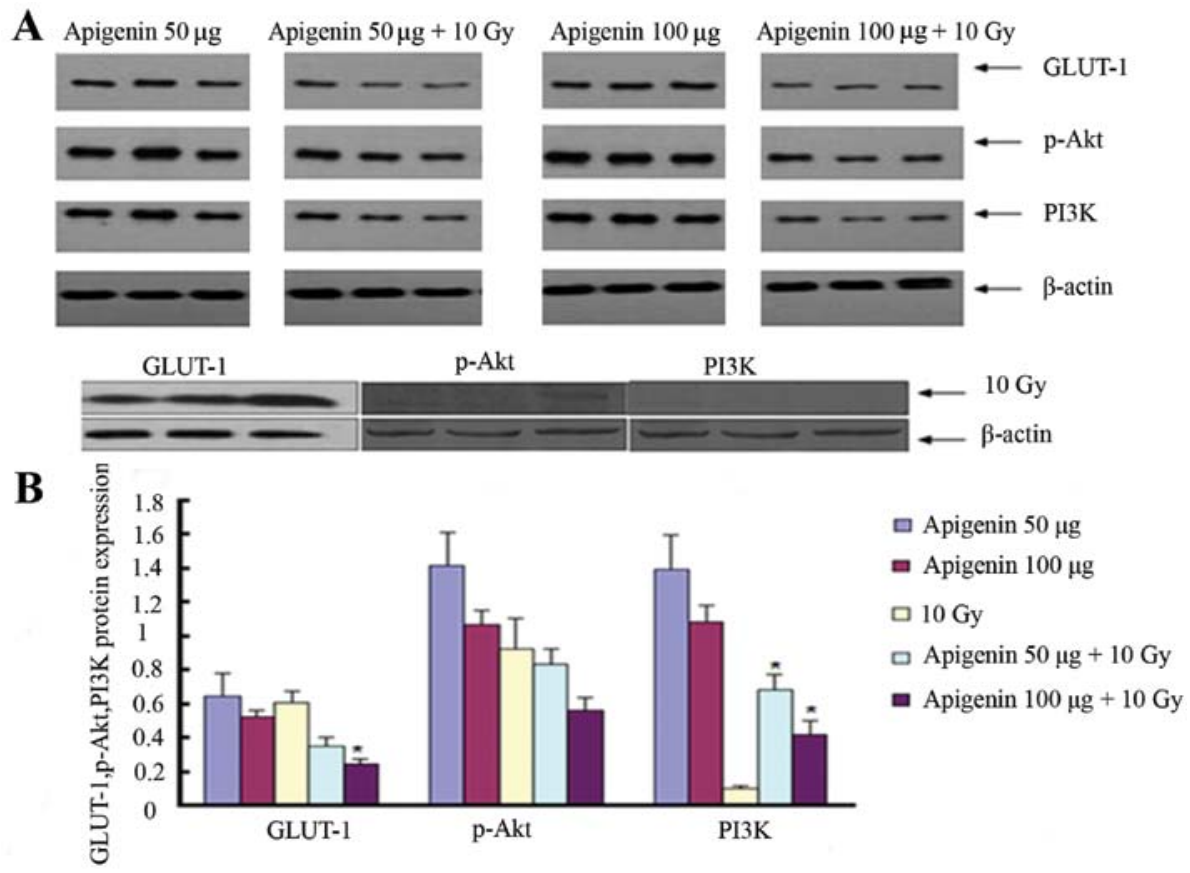

Figure 6. Frst experiment. (A) Western blot analysis shows the expression of GLUT-1, p-Akt and PI3K protein in xenograft tumors. (B) ${ }^{*} \mathrm{P}<0.05$, indicated that there were significant differences in the tumor protein compared to the $10 \mathrm{~Gy}$ group.

apigenin plus GLUT-1 AS-ODNs plus 10 Gy group compared to the control group $(\mathrm{P}<0.05$; Fig. 7). The expression of PI3K was also lower, but not significant $(\mathrm{P}>0.05)$. The expression of GLUT-1 was significantly higher in the 10 Gy X-ray group compared to the control group ( $\mathrm{P}<0.05$; Fig. 7). The expression of $\mathrm{p}-\mathrm{Akt}$ and PI3K was higher, but not significant $(\mathrm{P}>0.05)$. 


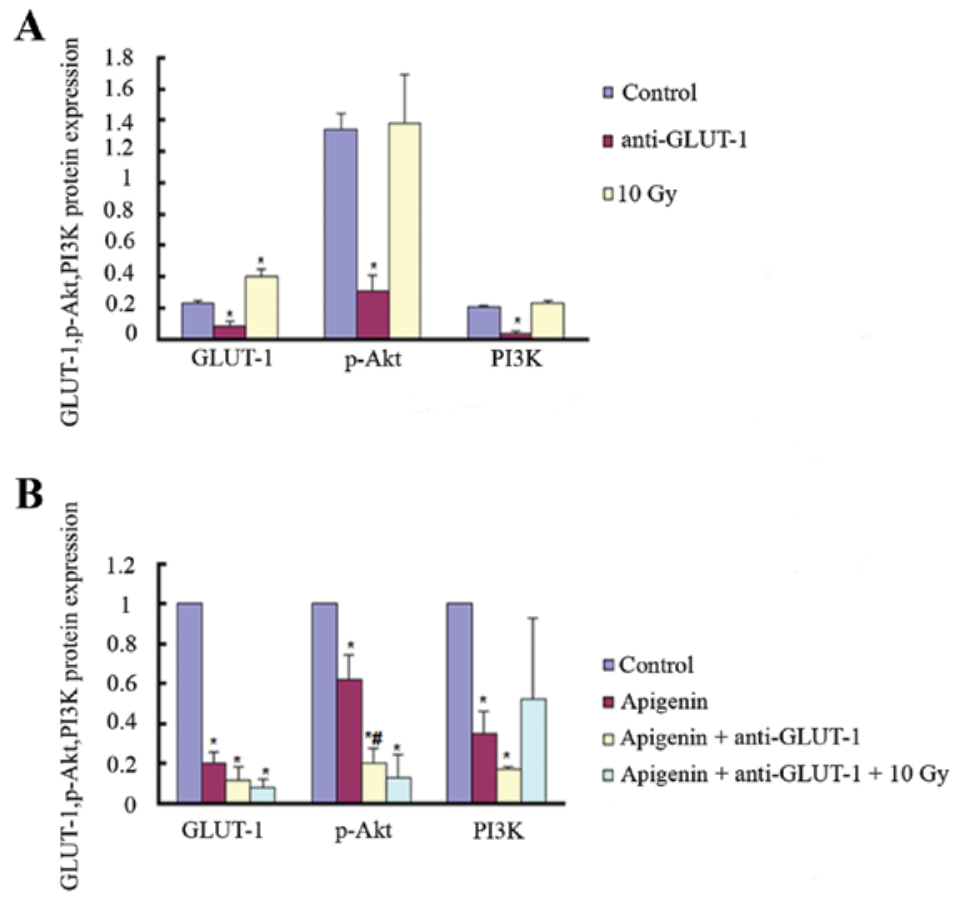

Figure 7. Second experiment. Western blot analysis shows the expression of GLUT-1, p-Akt and PI3K protein in xenograft tumors. (A) ${ }^{*} \mathrm{P}<0.05$, indicated that there were significant differences in the tumor protein compared to the control group. (B) ${ }^{*} \mathrm{P}<0.05$, indicated that there were significant differences in the tumor protein compared to the control group. ${ }^{\#} \mathrm{P}<0.05$, indicated that there were significant differences in the tumor protein between the apigenin+anti-GLUT- 1 group and the apigenin group.

The expression of p-Akt was significantly lower in the apigenin plus GLUT-1 AS-ODNs group compared to the apigenin group $(\mathrm{P}<0.05$; Fig. 7). The expression of GLUT-1 and PI3K was also lower, although not significant $(\mathrm{P}>0.05)$.

\section{Discussion}

Radioresistance is one of the major obstacles in the treatment of laryngeal carcinoma, however, the mechanism behind the radioresistance of laryngeal carcinoma remains unclear. We demonstrated previously that GLUT-1 AS-ODNs inhibit glucose uptake and proliferation in Hep-2 cells by inhibiting the expression of GLUT-1 (14). Additional studies revealed that the overexpression of GLUT-1 mRNA and protein may play a role in the radioresistance of Hep-2 cells and that GLUT-1 AS-ODNs enhanced the radioresistance of laryngeal carcinoma Hep-2 cells by suppressing the expression of GLUT-1 protein and inducing tumor cell apoptosis (15). In vivo, the peritumoral injection of GLUT-1 AS-ODNs may enhance the radiosensitivity of xenografts by inhibiting GLUT-1 mRNA and protein expression (15). Previous findings have shown that the overexpression of GLUT-1 was associated with tumor radioresistance (34-36). Therefore, we hypothesized that inhibiting the expression of GLUT-1 may sensitize laryngeal carcinoma to radiotherapy and that GLUT-1 is a therapeutic target in laryngeal carcinoma.

In the second experiment in the present study, the results revealed that tumor size and weight did not decrease significantly in the $10 \mathrm{~Gy}$ group compared to the control group. However, GLUT-1 mRNA and protein were significantly higher in the 10 Gy group compared to the control group, which was consistent with previous studies.

As determined above, the mechanism behind the radioresistance of laryngeal carcinoma is unclear and likely caused by an interplay of multiple factors. With the development of molecular biology-based techniques, the factors that regulate GLUT-1 have been gradually clarified. Specifically, several signaling pathways regulate GLUT-1, including the PI3K/Akt pathway. Melstrom et al (16), Jacobs et al (37) and Wieman et al (38) demonstrated that PI3K/Akt signaling may play a role in the translocation of GLUT-1 from the cytosol to serous membrane, and that activation of the PI3K/Akt pathway is associated with to GLUT-1 overexpression. Extensive study has been performed to assess the role of the PI3K/Akt signaling pathway in radioresistance, which has revealed that it is associated with three mechanisms of radioresistance: intrinsic radiation resistance, tumor cell proliferation and hypoxia (39). $\mathrm{Ni}$ et al found that prostate cancer radioresistance was associated with activation of the PI3K/Akt/mTOR signaling pathway (22). Consistent with this finding, Chang et al reported that inhibition of the PI3K/Akt pathway could increase the radiosensitivity of prostate cancer and induce apoptosis (24). In addition, Zhuang et al stated that inhibiting the PI3K/Akt/mTOR pathway increased the radiosensitivity of malignant gliomas (23), whereas Kao et al found that inhibiting PI3K/Akt improved the radiosensitivity of malignant glioma and decreased the efficiency by which cells repair DNA damage (26). However, previous reports have assessed the effect of the PI3K/Akt signaling pathway on GLUT-1 expression and the mechanism of radioresistance of laryngeal carcinoma in vivo.

The second experiment in the present study revealed that GLUT-1 protein expression was higher in the 10 Gy group compared to the control group ( $\mathrm{P}<0.05$; Fig. 7$)$, and $\mathrm{p}-\mathrm{Akt}$ and PI3K were also higher in the $10 \mathrm{~Gy}$ group, although the increase was not significant $(\mathrm{P}>0.05)$. This suggests that activation of the PI3K/Akt signaling pathway may play a role in GLUT-1-induced radioresistance in laryngeal carcinoma. 
Apigenin is a natural phytoestrogen flavonoid that exerts biological effects including anti-oxidative, anti-inflammatory, antiviral, immune-adjusting, anti-mutation and anticancer activities (27). Shukla et al found that apigenin may inhibit the development of prostate cancer by downregulating the PI3K/Akt/ FoxO signaling pathway (28). In addition, Lee et al found that apigenin may inhibit the PI3K/Akt pathway and the function of the integrin- $\beta 4$ protein to inhibit hepatocyte growth factor (HGF)-induced invasion and metastasis (29). Zhu et al reported that apigenin may induce bladder cancer T24 cell apoptosis and $\mathrm{G}_{2} / \mathrm{M}$ cell cycle arrest by upregulating Bax and Bad, activating caspase-3 and PARP, inhibiting the PI3K/Akt pathway and downregulating the anti-apoptotic proteins Bcl-2 and Bcl-X (30). Gao et al reported that apigenin improved the chemosensitivity of BEL-7402/ADM liver cancer cells to Adriamycin by suppressing the PI3K/Akt/Nrf2 pathway (31). Melstrom et al (16) demonstrated that GLUT-1 mRNA and protein expression decreased in a time- and dose-dependent manner in apigenin-treated CD-18 and S2-013 human pancreatic cancer cells, suggesting that apigenin inhibited GLUT-1 expression at the transcriptional and translational levels. Apigenin also downregulated the expression of p-Akt. The authors also reported that GLUT-1 mRNA and protein levels decreased in CD-18 and S2-013 cells treated with the PI3K inhibitors Wortmannin and LY294002. Therefore, apigenin may decrease GLUT-1 expression by suppressing the PI3K/Akt pathway, thereby inhibiting glucose uptake and inducing apoptosis in pancreatic cancer cells (16). We demonstrated previously that the chemoresistance of Hep-2 laryngeal carcinoma cells to cisplatin is associated with the expression of GLUT-1 and PI3K/ Akt signaling and that apigenin may increase the sensitivity of laryngeal carcinoma to cisplatin by inhibiting GLUT-1 and p-Akt expression (32). Therefore, we hypothesized that apigenin may improve the radiosensitivity of laryngeal carcinoma xenografts by inhibiting GLUT-1 expression and suppressing PI3K/Akt signaling and that apigenin could improve the effects of GLUT-1 AS-ODNs in xenografts.

In the first experiment of the present study before X-ray radiation (the 10 Gy group was equivalent to the control group), $100 \mu \mathrm{g}$ apigenin reduced tumor size significantly compared to the 10 Gy group 12 days after treatment $(\mathrm{P}<0.05)$. In addition, $50 \mu \mathrm{g}$ and $100 \mu \mathrm{g}$ apigenin reduced tumor size significantly compared to the 10 Gy group 19 days after treatment $(\mathrm{P}<0.05)$, suggesting that apigenin inhibited xenograft tumor growth. After X-ray radiation, $100 \mu \mathrm{g}$ apigenin plus $10 \mathrm{~Gy}$ reduced tumor size significantly compared to the 10 Gy group 27 days after treatment $(\mathrm{P}<0.05)$, suggesting that apigenin sensitized the xenografts to radiotherapy.

However, in the second experiment, apigenin reduced tumor size compared to the control group, although not significantly $(\mathrm{P}>0.05)$, which may have been due to the different apigenin dosing intervals used in the two experiments. GLUT-1 AS-ODNs reduced tumor size significantly compared to the control group 17 days after treatment $(\mathrm{P}<0.05)$. In addition, GLUT-1 AS-ODNs, apigenin plus GLUT-1 AS-ODNs and apigenin plus GLUT-1 AS-ODNs plus 10 Gy reduced tumor size significantly compared to the control 24 days after treatment $(\mathrm{P}<0.05)$, suggesting that these treatments inhibited xenograft tumor growth. In addition, apigenin, GLUT-1 AS-ODNs, 10 Gy X-ray radiation, apigenin plus GLUT-1 AS-ODNs and apigenin plus GLUT-1 AS-ODNs plus 10 Gy X-ray radiation all increased tumor cell apoptosis, as detected using TUNEL staining. Apigenin plus GLUT-1 AS-ODNs also enhanced the effect of apigenin or GLUT-1 AS-ODNs alone on tumor cell apoptosis significantly. Apigenin plus GLUT-1 AS-ODNs significantly enhanced the effects of X-ray radiation on tumor cell apoptosis. Collectively, these results suggest that apigenin and GLUT-1 AS-ODNs inhibited laryngeal carcinoma growth. The combination of apigenin and GLUT-1 AS-ODNs enhanced the effects of apigenin or GLUT-1 AS-ODNs alone. In addition, apigenin and apigenin plus GLUT-1 AS-ODNs improved the radiosensitivity of laryngeal carcinoma.

We investigated the molecular mechanisms by which apigenin and GLUT-1 AS-ODNs enhanced the radiosensitivity and suppressed xenograft tumor growth. The expression of GLUT-1, Akt and PI3K mRNA was significantly lower in the $100 \mu \mathrm{g}$ apigenin and GLUT-1 AS-ODNs groups compared to the control group. In addition, the combination of apigenin plus GLUT-1 AS-ODNs significantly enhanced the effects of apigenin or GLUT-1 AS-ODNs alone on inhibiting the expression of GLUT-1 or PI3K mRNA. The expression of GLUT-1, $A k t$ and $P I 3 K$ mRNA was significantly lower in the apigenin plus GLUT-1 AS-ODNs plus 10 Gy group compared to the $10 \mathrm{~Gy}$ group. In addition, although the GLUT-1 expression was lower in the $100 \mu \mathrm{g}$ apigenin plus $10 \mathrm{~Gy}$ group compared to the 10 Gy group, the levels of GLUT-1, Akt and PI3K mRNA were higher in the $50 \mu \mathrm{g}$ apigenin plus $10 \mathrm{~Gy}$ group compared to the 10 Gy group. It is possible that apigenin is not a specific inhibitor of the PI3K/Akt signaling pathway or that these effects were caused by the injection dose or dosing methods used. We found similar results at the protein level.

In conclusion, the overexpression of GLUT-1 and increased activation of the PI3K/Akt signaling pathway may be involved in the radioresistance of laryngeal carcinoma in vivo. The effects of apigenin on inhibiting xenograft growth and enhancing xenograft radiosensitivity may be associated with suppressing the expression of GLUT-1 via the PI3K/Akt pathway. In addition, apigenin may enhance the effects of GLUT-1 AS-ODNs via the same mechanism.

\section{Acknowledgements}

The present study was supported by the Traditional Chinese Medicine Scientific Research Project of Zhejiang Province, China (grant no. 2013ZA075), Health Department of Zhejiang Province, China (grant no. 2015116850), and the National Natural Science Foundation of China (grant nos. 81172562 and 81372903).

\section{References}

1. Karlsson TR, Al-Azzawe M, Aziz L, Hurman D and Finizia C: Survival outcome depending on different treatment strategies in advanced stages III and IV laryngeal cancers: An audit of data from two European centres. Eur Arch Otorhinolaryngol 271: 547-554, 2014.

2. Haapaniemi A, Koivunen P, Saarilahti K, Kinnunen I, Laranne J, Aaltonen LM, Närkiö M, Lindholm P, Grénman R, Mäkitie A, et al; The Finnish Head and Neck Oncology Working Group: Laryngeal cancer in Finland: A 5-year follow-up study of 366 patients. Head Neck 00: 00-00, 2014.

3. Siegel R, Ma J, Zou Z and Jemal A: Cancer statistics, 2014. CA Cancer J Clin 64: 9-29, 2014. 
4. Nichols AC, Whelan F, Basmaji J, Dhaliwal S, Dowthwaite S, Chapeskie C, Read N, Palma DA, Fung K, Venkatesan V, et al: $\mathrm{Ki}-67$ expression predicts radiotherapy failure in early glottic cancer. J Otolaryngol Head Neck Surg 41: 124-130, 2012.

5. Nix P, Cawkwell L, Patmore H, Greenman J and Stafford N: Bcl-2 expression predicts radiotherapy failure in laryngeal cancer. $\mathrm{Br} \mathrm{J}$ Cancer 92: 2185-2189, 2005.

6. Yoshida K, Sasaki R, Nishimura H, Okamoto Y, Suzuki Y, Kawabe T, Saito M, Otsuki N, Hayashi Y, Soejima T, et al: Nuclear factor-kappaB expression as a novel marker of radioresistance in early-stage laryngeal cancer. Head Neck 32: 646-655, 2010.

7. Bussink J, van der Kogel AJ and Kaanders JH: Activation of the PI3-K/AKT pathway and implications for radioresistance mechanisms in head and neck cancer. Lancet Oncol 9: 288-296, 2008.

8. Jonathan RA, Wijffels KI, Peeters W, de Wilde PC, Marres HA, Merkx MA, Oosterwijk E, van der Kogel AJ and Kaanders JH: The prognostic value of endogenous hypoxia-related markers for head and neck squamous cell carcinomas treated with ARCON. Radiother Oncol 79: 288-297, 2006.

9. Hoogsteen IJ, Marres HA, Bussink J, van der Kogel AJ and Kaanders JH: Tumor microenvironment in head and neck squamous cell carcinomas: Predictive value and clinical relevance of hypoxic markers. A review. Head Neck 29: 591-604, 2007.

10. Bussink J, Kaanders JH and van der Kogel AJ: Tumor hypoxia at the micro-regional level: Clinical relevance and predictive value of exogenous and endogenous hypoxic cell markers. Radiother Oncol 67: 3-15, 2003

11. Airley R, Loncaster J, Davidson S, Bromley M, Roberts S, Patterson A, Hunter R, Stratford I and West C: Glucose transporter glut-1 expression correlates with tumor hypoxia and predicts metastasis-free survival in advanced carcinoma of the cervix. Clin Cancer Res 7: 928-934, 2001.

12. Luo XM, Zhou SH and Fan J: Glucose transporter-1 as a new therapeutic target in laryngeal carcinoma. J Int Med Res 38 $1885-1892,2010$

13. Rademakers SE, Lok J, van der Kogel AJ, Bussink J and Kaanders JH: Metabolic markers in relation to hypoxia; staining patterns and colocalization of pimonidazole, HIF-1 $\alpha$, CAIX, LDH-5, GLUT-1, MCT1 and MCT4. BMC Cancer 11: 167-176, 2011.

14. Zhou SH, Fan J, Chen XM, Cheng KJ and Wang SQ: Inhibition of cell proliferation and glucose uptake in human laryngeal carcinoma cells by antisense oligonucleotides against glucose transporter-1. Head Neck 31: 1624-1633, 2009.

15. Yan SX, Luo XM, Zhou SH, Bao YY, Fan J, Lu ZJ, Liao XB Huang YP, Wu TT and Wang QY: Effect of antisense oligodeoxynucleotides glucose transporter-1 on enhancement of radiosensitivity of laryngeal carcinoma. Int J Med Sci 10: 1375-1386, 2013

16. Melstrom LG, Salabat MR, Ding XZ, Milam BM, Strouch M Pelling JC and Bentrem DJ: Apigenin inhibits the GLUT-1 glucose transporter and the phosphoinositide 3-kinase/Akt pathway in human pancreatic cancer cells. Pancreas 37: 426-431, 2008.

17. Suh HN and Han HJ: Fibronectin-induced VEGF receptor and calcium channel transactivation stimulate GLUT-1 synthesis and trafficking through PPAR $\gamma$ and TC10 in mouse embryonic stem cells. Stem Cell Res (Amst) 10: 371-386, 2013

18. Zhao K, Yang SY, Zhou SH, Dong MJ, Bao YY and Yao HT: Fluorodeoxyglucose uptake in laryngeal carcinoma is associated with the expression of glucose transporter-1 and hypoxiainducible-factor- $1 \alpha$ and the phosphoinositide 3-kinase/protein kinase B pathway. Oncol Lett 7: 984-990, 2014

19. Gonnella R, Santarelli R, Farina A, Granato M, D'Orazi G, Faggioni A and Cirone M: Kaposi sarcoma associated herpesvirus (KSHV) induces AKT hyperphosphorylation, bortezomib-resistance and GLUT-1 plasma membrane exposure in THP-1 monocytic cell line. J Exp Clin Cancer Res 32: 79, 2013.

20. Heavey S, O'Byrne KJ and Gately K: Strategies for co-targeting the PI3K/AKT/mTOR pathway in NSCLC. Cancer Treat Rev 40 : 445-456, 2014

21. Kaidar-Person O, Lai C, Kuten A and Belkacemi Y; AROME: 'The Infinite Maze' of breast cancer, signaling pathways and radioresistance. Breast 22: 411-418, 2013.
22. Ni J, Cozzi P, Hao J, Beretov J, Chang L, Duan W, Shigdar S, Delprado W, Graham P, Bucci J, et al: Epithelial cell adhesion molecule (EpCAM) is associated with prostate cancer metastasis and chemo/radioresistance via the PI3K/Akt/mTOR signaling pathway. Int J Biochem Cell Biol 45: 2736-2748, 2013.

23. Zhuang W, Qin Z and Liang Z: The role of autophagy in sensitizing malignant glioma cells to radiation therapy. Acta Biochim Biophys Sin (Shanghai) 41: 341-351, 2009

24. Chang L, Graham PH, Hao J, Ni J, Bucci J, Cozzi PJ, Kearsley JH and Li Y: Acquisition of epithelial-mesenchymal transition and cancer stem cell phenotypes is associated with activation of the $\mathrm{PI} 3 \mathrm{~K} / \mathrm{Akt} / \mathrm{mTOR}$ pathway in prostate cancer radioresistance. Cell Death Dis 4: e875, 2013.

25. Carón RW, Yacoub A, Zhu X, Mitchell C, Han SI, Sasazuki T, Shirasawa S, Hagan MP, Grant S and Dent P: H-RAS V12-induced radioresistance in HCT116 colon carcinoma cells is heregulin dependent. Mol Cancer Ther 4: 243-255, 2005.

26. Kao GD, Jiang Z, Fernandes AM, Gupta AK and Maity A: Inhibition of phosphatidylinositol-3-OH kinase/Akt signaling impairs DNA repair in glioblastoma cells following ionizing radiation. J Biol Chem 282: 21206-21212, 2007.

27. Bao YY, Zhou SH, Fan J and Wang QY: Anticancer mechanism of apigenin and the implications of GLUT-1 expression in head and neck cancers. Future Oncol 9: 1353-1364, 2013.

28. Shukla S, Bhaskaran N, Babcook MA, Fu P, Maclennan GT and Gupta S: Apigenin inhibits prostate cancer progression in TRAMP mice via targeting PI3K/Akt/FoxO pathway. Carcinogenesis 35: 452-460, 2014

29. Lee WJ, Chen WK, Wang CJ, Lin WL and Tseng TH: Apigenin inhibits HGF-promoted invasive growth and metastasis involving blocking PI3K/Akt pathway and beta 4 integrin function in MDA-MB-231 breast cancer cells. Toxicol Appl Pharmacol 226: 178-191, 2008.

30. Zhu Y, Mao Y, Chen H, Lin Y, Hu Z, Wu J, Xu X, Xu X, Qin J and Xie L: Apigenin promotes apoptosis, inhibits invasion and induces cell cycle arrest of T24 human bladder cancer cells. Cancer Cell Int 13: 54, 2013.

31. Gao AM, Ke ZP, Wang JN, Yang JY, Chen SY and Chen H: Apigenin sensitizes doxorubicin-resistant hepatocellular carcinoma BEL-7402/ADM cells to doxorubicin via inhibiting PI3K/Akt/Nrf2 pathway. Carcinogenesis 34: 1806-1814, 2013.

32. Xu YY, Wu TT, Zhou SH, Bao YY, Wang QY, Fan J and Huang YP: Apigenin suppresses GLUT-1 and p-AKT expression to enhance the chemosensitivity to cisplatin of laryngeal carcinoma Hep-2 cells: An in vitro study. Int J Clin Exp Pathol 7: 3938-3947, 2014.

33. Shukla S and Gupta S: Apigenin-induced cell cycle arrest is mediated by modulation of MAPK, PI3K-Akt, and loss of cyclin D1 associated retinoblastoma dephosphorylation in human prostate cancer cells. Cell Cycle 6: 1102-1114, 2007.

34. Huang XQ, Chen X, Xie XX, Zhou Q, Li K, Li S, Shen LF and Su J: Co-expression of CD147 and GLUT-1 indicates radiation resistance and poor prognosis in cervical squamous cell carcinoma. Int J Clin Exp Pathol 7: 1651-1666, 2014.

35. Kunkel M, Moergel M, Stockinger M, Jeong JH, Fritz G, Lehr HA and Whiteside TL: Overexpression of GLUT-1 is associated with resistance to radiotherapy and adverse prognosis in squamous cell carcinoma of the oral cavity. Oral Oncol 43: 796-803, 2007.

36. Doki Y, Takachi K, Ishikawa O, Sasaki Y, Miyashiro I, Ohigashi H, Yano M, Ishihara R, Tsukamoto Y, Nishiyama K, et al: Reduced tumor vessel density and high expression of glucose transporter 1 suggest tumor hypoxia of squamous cell carcinoma of the esophagus surviving after radiotherapy. Surgery 137: 536-544, 2005.

37. Jacobs SR, Herman CE, Maciver NJ, Wofford JA, Wieman HL, Hammen JJ and Rathmell JC: Glucose uptake is limiting in T cell activation and requires CD28-mediated Akt-dependent ad independent pathways. J Immunol 180: 4476-4486, 2008.

38. Wieman HL, Wofford JA and Rathmell JC: Cytokine stimulation promotes glucose uptake via phosphatidylinositol-3 kinase/Akt regulation of Glut 1 activity and trafficking. Mol Biol Cell 18: 1437-1446, 2007

39. Schuurbiers OC,Kaanders JH, van derHeijden HF, Dekhuijzen RP, Oyen WJ and Bussink J: The PI3-K/AKT-pathway and radiation resistance mechanisms in non-small cell lung cancer. $\mathrm{J}$ Thorac Oncol 4: 761-767, 2009. 